\title{
Correlation between sonic anemometers at three heights within a mixed temperate forest
}

\author{
Mark Halliday \\ This manuscript was prepared under the supervision of Professor Jon Warland, \\ School of Environmental Sciences, Ontario Agricultural College.

\begin{abstract}
Correlation coefficients were determined for the horizontal and vertical components from three sonic anemometers in a mixed temperate forest. It was found that the vertical structure of the canopy is important for two point correlations within the canopy. This was especially noticed for horizontal motion due to differences in structure between the upper and lower parts of the canopy, which affected the correlations between these parts. This suggests that there is a decoupling trend between these parts of the canopy. Typically the anemometers with smaller vertical height separations were shown to have stronger correlations than the larger height separations.
\end{abstract}

U nderstanding atmospheric structure and turbulence directly above and within a forest canopy is important for learning how gases and pollutants move within a forest. Much work has been conducted using single point statistics including a model wheat canopy wind tunnel study by Brunet et al. ${ }^{1}$ However, it has been suggested that single point statistics tend to underestimate the correlation in flow between positions in the canopy, especially in the vertical component. ${ }^{2}$ For this reason, analysis has been conducted using two point statistics by Shaw et $\mathrm{al}^{2}$ in a model wheat canopy wind tunnel, by Baldocchi and Meyers ${ }^{3}$ in a deciduous forest and in a rainforest by Kruijt et al. ${ }^{4}$

Through previous work, it has been determined that there is a substantial breakdown of eddies from the time they enter the canopy, at the top, to when the reach the forest floor. ${ }^{4}$ Using power and coherence spectral analysis, Kruijt et $\mathrm{al}^{4}$ were able to show a decoupling trend between the upper and lower canopy. However, this was for a rainforest canopy which typically has a greater mass of tree foliage. In a deciduous forest, which is more applicable to this study, a similar trend was found by Baldocchi and Meyers. ${ }^{3}$ They determined that in the top $20 \%$ of the canopy, where approximately $70 \%$ of tree foliage exists, there was greater turbulence and stronger shear when compared to the lower canopy. $^{3}$

This paper studies two point correlations between sonic anemometers in a mixed temperate forest. Three anemometers were set up at three vertical heights within the forest and then two point correlations were determined for both the horizontal and vertical components.

\section{METHODS}

\section{Site Description}

The experimental measurements were taken at Canadian Forces Base Borden ( $\left.44^{\circ} 16^{\prime} 18^{\prime \prime} \mathrm{N}, 79^{\circ} 54^{\prime} 45^{\prime \prime} \mathrm{W}\right)$, located in Southern Ontario. The site is an Environment Canada Atmospheric Research Station in a heavily forested region at the north end of the base. The site contains a $45 \mathrm{~m}$ tower with small trailers at its base to house the meteorological instruments, as well as a shorter $2 \mathrm{~m}$ tower to the southeast, used for making understory measurements. The measurement fetch is small to the north, disturbed by a road and farmland. However, the remaining area is a concentrated forest, excluding access roads. The prevailing wind at this location is from the westerly direction. This provides an upwind fetch of approximately $1300 \mathrm{~m}$ during stable conditions and about $150 \mathrm{~m}$ during unstable conditions at a tower height of $33 \mathrm{~m} .{ }^{5}$

The forest canopy is approximately $20-25 \mathrm{~m}$ in height and is composed of mainly aspen, red maple and ash trees to the south of the tower and coniferous trees to the north. At the time of the study the vegetation was in full leaf, providing a relatively dense upper canopy. Roughly $90 \%$ of the tree foliage, in the canopy, was between the 13 and $25 \mathrm{~m}$ anemometers. The understory vegetation consisted of short (roughly $1 \mathrm{~m}$ in height) ferns and small shrubs as well as saplings at various heights.

\section{Experimental Setup}

The experiment operated from 10 June until 11 September 2009. Three CSAT three-dimensional sonic anemometers 
(Model CSAT3, Campbell Scientific Inc, Logan UT) were deployed on site. Two anemometers were located on the main $45 \mathrm{~m}$ tower, at 13 and $25 \mathrm{~m}$; the third anemometer was positioned at the top of a secondary non-permanent $2 \mathrm{~m}$ tower, approximately $20 \mathrm{~m}$ north-east of the main tower. The two anemometers on the main tower were attached with approximately $2 \mathrm{~m}$ booms extending horizontally outward from the tower. The boom at a height of $13 \mathrm{~m}$ extended to the east with the anemometer directed towards the east. At $25 \mathrm{~m}$, a boom extended to the south and the anemometer was positioned in a southerly direction. The $2 \mathrm{~m}$ anemometer on the secondary tower was directed towards the south. The measurements of sonic wind speed were taken at $10 \mathrm{~Hz}$ and stored on a computer in a trailer at the base of the main tower.

\section{Data Analysis}

The analysis of this data was completed using Matlab software (R2006a, The MathWorks, Inc.). Each sonic anemometer measured the three sonic wind speed components; horizontal $(u)$, stream wise $(v)$ and vertical $(w)$, along with sonic temperature $(T)$ at each height. The mean, standard deviation, covariance (equation 1) and horizontal wind speed (equation 2); were calculated from the $10 \mathrm{~Hz}$ output data and compiled into half hour averages. In equations 1 and 2 the over-bar denotes the mean wind speed and the prime denotes the perturbation from the mean.

$$
\begin{aligned}
& \operatorname{cov}_{u w}=\overline{u w} \\
& s=\sqrt{\bar{u}^{2}+\bar{y}^{2}}
\end{aligned}
$$

Correlation coefficients were then calculated for each half hour using equation 3, where $\sigma$ represents the standard deviation for the component indicated by the subscript. The correlation coefficients were determined for total combined horizontal motion, which includes both $u$ and $v$ components together (denoted $\mathrm{S}$ ), and also for the vertical component $w$. The correlation coefficients calculated for $\mathrm{S}$ are as follows; $R_{5252}, R_{52513}, R_{52525}$ and $R_{513525}$ : while for $w$ they are $R_{\text {warz }}, \quad R_{\text {waw1z: }} \quad \boldsymbol{R}_{\text {waw } 2 \mathrm{~s}}$ and $R_{w 1 \text { sw } 2 \text {; }}$;here 2,13 , and 25 are the anemometer heights. Plots were generated for the correlations in time series and also for mean correlations at each height separation.

$$
R_{u W}=\frac{e 0 v_{\mathrm{wW}}}{\sigma_{\mathrm{u}} \sigma_{w}}
$$

These correlation coefficients where only determined for times when the cup wind speed at a height of $25 \mathrm{~m}$ was greater than $2.5 \mathrm{~m} / \mathrm{s}$. Additionally, times with standard deviations greater than 2 were omitted from the calculations because it was assumed that during these periods the instrument was malfunctioning.

Finally a t-test was completed for the time series of
$R_{5252}, R_{52513}$ and $R_{52525}$. It was used to determine if there was a significant difference in the mean RS for each height separation. It was also used to determine if the mean at each height separation was significantly different than zero.
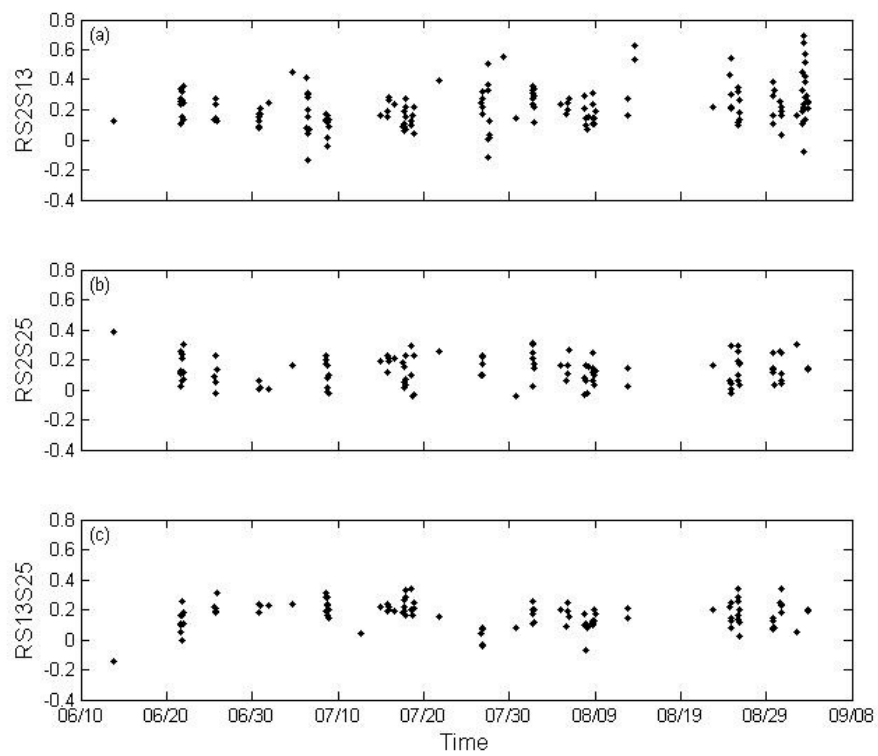

Figure 1: Correlation Coefficients for the Time Series of Combined Horizontal Components.

(a) Correlation for 2 and $13 \mathrm{~m}$ Anemometer

(b) Correlation for 2 and $25 \mathrm{~m}$ Anemometer

(c) Correlation for 13 and 25 m Anemometer
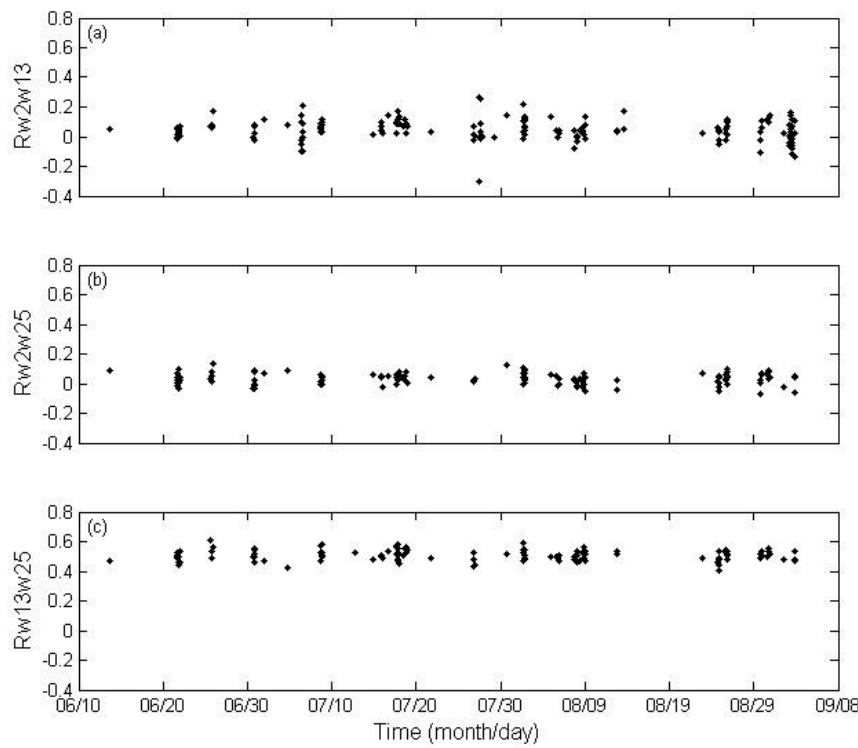

Figure 2: Correlation Coefficients for the Time Series of Vertical Spatial Correlation.

(a) Correlation between the 2 and $13 \mathrm{~m}$ Anemometer

(b) Correlation between the 2 and $25 \mathrm{~m}$ Anemometer

(c) Correlation between the 13 and $25 \mathrm{~m}$ Anemometer 


\section{RESULTS}

Figure 1 shows the time series for the correlation of the combined horizontal wind components $\left(R s_{i} s_{j}\right)$ between the three anemometer heights $(2 \mathrm{~m}, 13 \mathrm{~m}$, and $25 \mathrm{~m})$. In Figure 1a, the correlation is given between the anemometers at heights of 2 and $13 \mathrm{~m}$. The mean value over the entire measurement period was $0.22 \pm 0.098$. At the 2 and $25 \mathrm{~m}$ heights, given in Figure 1b, a mean correlated value of 0.13 \pm 0.097 was found. Figure 1c, shows the correlation between the 13 and $25 \mathrm{~m}$ heights with a mean of $0.16 \pm 0.087$. In Figure 2, the time series for the vertical spatial correlation is shown. In Figure 2a, at heights of 2 and $13 \mathrm{~m}$, the mean correlation value was $0.04 \pm 0.072$; whereas, in Figure 2b, at the 2 and $25 \mathrm{~m}$ heights, a correlation of $0.03 \pm 0.039$ was found. Figure 2c shows at 13 and $25 \mathrm{~m}$ heights, a correlation of $0.50 \pm 0.035$ was determined.

The single mean correlation value from each time series given in Figure 1 was plotted in Figure 3a against the vertical separation between the three anemometers. A fourth correlation point was then created with a zero height separation giving a mean correlation coefficient of 1 . In Figure 3b mean values from each of the three vertical correlation time series shown in Figure 2 were plotted against the vertical anemometer height separation. Again a fourth correlation of 1 was added to show when there is no height separation between anemometers.

All the t-tests showed significant differences between the mean RS values at different height separations with $p \leq 0.01$.
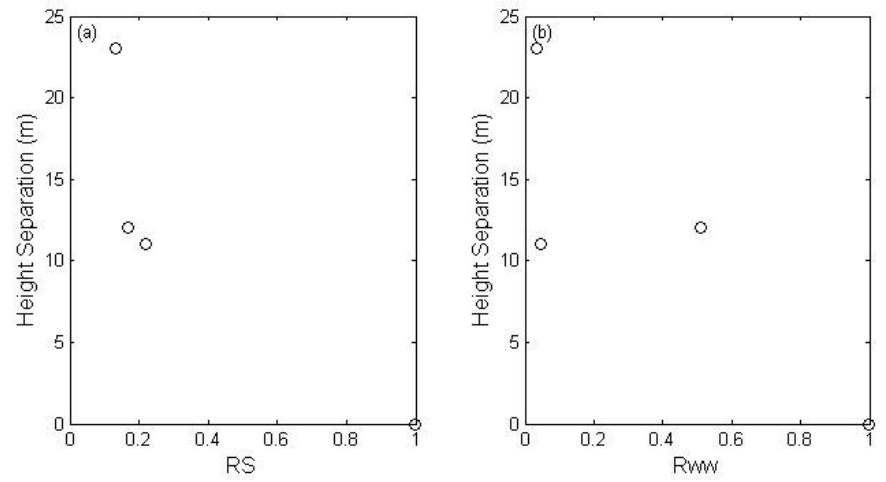

Figure 3: Mean Correlation Coefficients Against Anemometer Height Separation.

(a) The plot for the Combined Horizontal Components (b) The plot for the Combined Vertical Spatial Correlation

\section{DISCUSSION}

\section{Horizontal Component Correlations}

The correlations for the horizontal components are more consistent when compared to the vertical component.

However, none of the three height separations appear to be dramatically more correlated than another. The strongest correlation is between the 2 and $13 \mathrm{~m}$ anemometers. At this level in the forest the horizontal motion is expected to be the most consistent compared with higher heights in the canopy where there is greater tree foliage. This is based on work completed by Kruijt et $\mathrm{al}^{4}{ }^{4}$ where it was shown that strong vertical decoupling between the top and bottom part of the canopy exists. This decoupling would affect the horizontal correlations if the vertical separation of the anemometers spans across these two levels. The correlation could potentially be reduced as a result of having the $2 \mathrm{~m}$ anemometer horizontally separated by $20 \mathrm{~m}$ from the taller tower. The correlations between 2 and $25 \mathrm{~m}$, along with the 13 and $25 \mathrm{~m}$ anemometers, are less significant compared with the 2 and $13 \mathrm{~m}$ correlation. This could be caused by the larger, more consistent, horizontal wind speed above the canopy at $25 \mathrm{~m}$. Once entering the canopy, the horizontal wind speed decreases significantly with interruptions from tree branches and leaves. Figure 1 shows that there is a large standard deviation for all three plots. This indicates that some points are well correlated and others are poorly correlated, suggesting there is high variability in the horizontal motion throughout the canopy.

The information gained from the t-tests suggests that the mean correlations for each height separation differ significantly from each other. This supports the hypothesis that there is strong decoupling between the upper and lower canopy. In addition, each mean was significantly different from zero, indicating that decoupling is not complete, but small correlations exist in the horizontal winds at different heights.

\section{Vertical Spatial Correlation}

When considering only the vertical wind component, the correlation between 13 and $25 \mathrm{~m}$ was greatest compared with the other height separations. It was expected that this correlation would be greater than the others, since a sweep of air is less disturbed when it first enters the canopy. As that sweep continues its downward motion it will become more disorganised with tree foliage interference, therefore vertical motions at the lower anemometers are less correlated with each other. For the 2 and $25 \mathrm{~m}$ correlation the low value could potentially be due to the $23 \mathrm{~m}$ height separation in which an eddy entering the canopy will break apart over that distance and the motion therefore becomes more disorganized. In Kruijt et $\mathrm{al}^{4}$ they found that strong sweeps of air entering the canopy would be unable to travel much below half the canopy height. This could explain the poor correlation for the $23 \mathrm{~m}$ height separation. It should be noted however, that the Kruijt et $\mathrm{al}^{4}$ measurements were made in a tropical rainforest and therefore the top portion of the canopy will be much denser than the forest used for our measurements. A similar trend is found in Shaw et $\mathrm{al}^{2}$ where the correlation decreases with vertical separation. This is apparent in results obtained in this study as the $12 \mathrm{~m}$ height separation is very well correlated compared to the $23 \mathrm{~m}$ separation. However, the $11 \mathrm{~m}$ separation, for 2 and $13 \mathrm{~m}$ anemometer heights, has a poor correlation which contradicts 
these findings. It is not surprising that there is this contradiction because once the eddy has broken apart it would not be expected to re-organize. Therefore it does not matter how close the anemometers are to each other a strong correlation should not be observed at this level in the canopy. This difference could be explained by recognizing that this study made measurements in an actual forest, whereas in Shaw et $\mathrm{al}^{2}$ their measurements were taken in a model wheat canopy. More analysis including power and coherence spectra should be conducted to further investigate these results.

\section{SUMMARY}

It was found that having a large height separation between the anemometers resulted in them being poorly correlated both for the horizontal and vertical components. This indicates that the further vertical distance an eddy travels through the canopy the more disorganized it becomes. This work seems to echo work done by others which suggested that the canopy structure is an important factor in understanding air movement through the forest. For horizontal motion, the results imply that at different heights within the canopy the motion is more organized or consistent than at other levels. The information gathered also tends to support the idea suggested in earlier work about the decoupling nature of the canopy. This concept will be influenced by the structure of the canopy and density of tree foliage.

\section{ACKNOWLEDGMENTS}

The work here has been funded by NSERC Strategic Project Grant \#351040. Thanks also to Jon Warland and Terry Gillespie for their comments and suggestions along with Environment Canada for the use of the Borden Forest Research Station.

\section{REFERENCES}

1. Brunet, Y., Finnigan, J.J., Raupach, M.R., 1994. A wind tunnel study of air flow in waving wheat: Single-point velocity statistics. Boundary-Layer Meteorology, 70, 95-132. 2. Shaw, R.H., Brunet, Y., Finnigan, J.J., Raupach, M.R., 1995. A wind tunnel study of air flow in waving wheat: Two-point velocity statistics. Boundary-Layer Meteorology, 76, 349-376.

3. Baldocchi, D.D., Meyers, T.P., 1988. Turbulence structure in a deciduous forest. Boundary-Layer Meteorology, 43, 345364.

4. Kruijt, B., Malhi, Y., Lloyd, J., Nobre, A.D., Miranda, A.C., Pereira, M.G., Culf, A., Grace, J., 2000. Turbulence statistics above and within two amazon rain forest canopies. Boundary-Layer Meteorology, 94, 297-331.

5. Staebler, R.M., Fuentes, J.D., Lee, X., Puckett, K.J., Neumann, H.H., Deary, M.J., Arnold, J.A., 2000. Long term flux measurements at the Borden Forest. CMOS Bulletin. 28, 9-16. 